\title{
Physical-Mechanical Behaviour and Processing Evolution of PMMA Bone Cement due to Graphene Addition
}

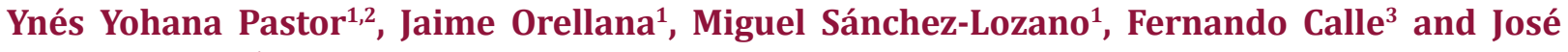 \\ Ygnacio Pastor ${ }^{1 *}$ \\ ${ }^{1}$ Departmento de Ciencia de los Materiales-CIME, Universidad Politécnica de Madrid, Spain \\ ${ }^{2}$ Facultad de Madicina, Universidad Complutense de Madrid, Spain
}

${ }^{3}$ Departamento de Ingeniería Electrónica-ISOM, Universidad Politécnica de Madrid, Spain

*Corresponding author: JY Pastor, Departmento de Ciencia de los Materiales-CIME, Universidad Politécnica de Madrid, Spain

\section{ARTICLE INFO}

Received:

Published: 幽 April 14, 2021

Citation: Ynés Yohana Pastor, Jaime Orellana, Miguel Sánchez, Fernando Calle, Jose Ygnacio Pastor. Physical-Mechanical Behaviour and Processing Evolution of PMMA Bone Cement due to Graphene Addition. Biomed J Sci \& Tech Res 35(1)2021. BJSTR. MS.ID.005646.

Keywords: PMMA Bone Cement; Graphene; Mechanical; Physical; Processing; Microstructural Behaviour; Orthopaedic and Trauma Surgery

\section{ABSTRACT}

Bone cement is wildly used in different arthroplasty surgical procedures, such as those regarding arthrosis and other prevalent illnesses. Its manufacture reaches high temperatures that can produce cell damage in the patients' surrounding tissue. We have studied how different percentages of HRGO can modify its mechanical, physical, and microstructural properties and processing. We concluded that a lower sintering temperature would be reached with this addition, making it more suitable for human use simultaneously as it reduces its adverse effects and contraindications. In contrast, the materials' density does not show significant changes, which indicates that the addition of HRGO does not increase porosity significantly. Lastly, the mechanical properties are reduced by almost $20 \%$. Nevertheless, these properties are high enough so that the new materials can still fulfil their structural function.

Abbreviations: PMMA: Polymethylmethacrylate; HRGO: Highly Reduced Graphene Oxide Layers; DSC: Differential Scanning Calorimetry; FESEM: Field Emission Scanning Electron Microscopy

\section{Introduction}

Bone cement is of paramount importance in Orthopaedic and trauma surgery due to its crucial role in the success of total joint replacement and newer treatments such as percutaneous vertebroplasty and kyphoplasty. Thus, it is widely used for implant fixations, acting as a space-filler that creates a tight space between different parts of the prosthesis and/or the prosthesis and the patient's organic material. It allows the absorption of small deformations as it has a modulus of elasticity and mechanical properties like those of the bone and one or two more orders of magnitude than the materials' prosthesis. In this way, in case of reaching high stresses, the bone will not break, much less the prosthesis, but the bone cement, which is easily replaceable. Even though the uses and availability of various bone cement's types have been explored, some adverse effects are associated with its use [1-3].
As bone cement is obtained from the mixture of two precursors that produce a strongly exothermic reaction, one of its main detriments is that it reaches over $60^{\circ} \mathrm{C}$ during the in-situ polymerization process. Temperatures over $46^{\circ} \mathrm{C}$ are associated with irreversible cellular death, thus producing significant damage to the surrounding tissues. The heat released during the cement's polymerization has also been related to intestinal obstruction due to adhesions and stricture of the ileum, as well as aseptic loosening of the prosthesis. Moreover, the curing time cannot be controlled during surgeries. It can either unnecessarily prolong them, causing subsequent thromboembolic events, or shorten them, preventing the surgeon from having enough time to complete the moulding, either before or during the surgery. Hence, in this paper, we have worked to optimise the structural properties of bone cement by the addition of HRGO, a biocompatible material, producing four 
different options, each one with a different weight percentage of graphene that covers three orders of magnitude [2,4-7].

Our goal is to determine the graphene's influence in the microstructural, mechanical, physical, and sintering behaviour to obtain improved materials that avoid the previously described problems and provide the optimal one for each anatomical structure. As reference material, MAT R, marketed PMMA bone cement CMW-1 Radiopaque of DePuy Ibérica was used. Our research was combined with different proportions (wt. \%) of HRGO. Both are biocompatible and suitable for direct human use. The analysed materials have been classified according to the different amounts of HRGO in the material (Table 1). The materials' processing has been carried out under controlled conditions through a device specifically built for this purpose. Nevertheless, for the sake of reproducibility and application of pressures like those used by a surgeon during his work, the method described by Frutos et al. was followed [6,8-10].

Table 1: Nomenclature according to different amounts of HRGO.

\begin{tabular}{|c|c|}
\hline HRGO Weight Per Cent (wt. \%) & Given Name \\
\hline 0,00 (reference material) & MAT R \\
\hline 0,01 & MAT 0.01 \\
\hline 0,10 & MAT 0.10 \\
\hline 0,50 & MAT 0.50 \\
\hline 1,00 & MAT 1.00 \\
\hline
\end{tabular}

For the temperature characterization during curing, four equidistance high-resolution K-thermocouples were employed to determine its evolution. A Mettler Toledo AG 245 balance, with 10-5 g resolution, has been used to ascertain the proportions of PMMA and HRGO for the processing materials and the absolute density, measured by pure ethanol immersion Archimedes method. Mechanical behaviour has been determined with an Instron 5866 electromechanical testing machine. The strength has been assessed from tensile tests, and the three-point bending (TPB) tests were employed to quantify de fracture toughness (Frutos et al.). Finally, the microstructural characterization has been done to ensure the quality of the material and the presence of defects, by observing it by FESEM (ZEISS Auriga), according to Palacios [6] et al.

Regarding the results shown in Figure 1, temperature increment T during curing is reduced drastically with the HRGO wt. $\%$ addition. Even with minimal additions, $0.01 \%$, reductions of $\mathrm{T}$ are relevant $\left(0,7^{\circ} \mathrm{C}\right)$.

Consequently, the damage will be reduced in adjacent tissues when the proportion of HRGO increases. The relevance of this accomplishment lies in its impact on the reduction of local necrosis. Moreover, the temperature in contact with the bone can be much higher since bones' thermal conductivity is three to five orders of magnitude smaller than our processing device's steel. As was foreseeable, the density (Table 2) decreases smoothly with additions of HRGO due to its lower density compared with PMMA. This fact can also be related to an increase in the size and number of pores in the sintered material associated with HRGO platelets' addition, which can play a role as pore nucleators.

Microstructural characterization showed that the material with the most notorious pore distribution is material MAT 1.00 (Figure 1 ), although it is not very different from that of the MAT R, with $0,00 \%$ HRGO, that exhibited the minor distribution. Finally, the materials' mechanical analysis showed an apparent decrease, up to $20 \%$, of tensile strength and fracture toughness as the percentage by weight of HRGO increased. This effect is related to the increment of the size and number of pores introduced by the HRGO addition. Nevertheless, this cutback is not of concern from a structural point of view, as bone cement with graphene maintains a residual capacity that meets its service requirements.

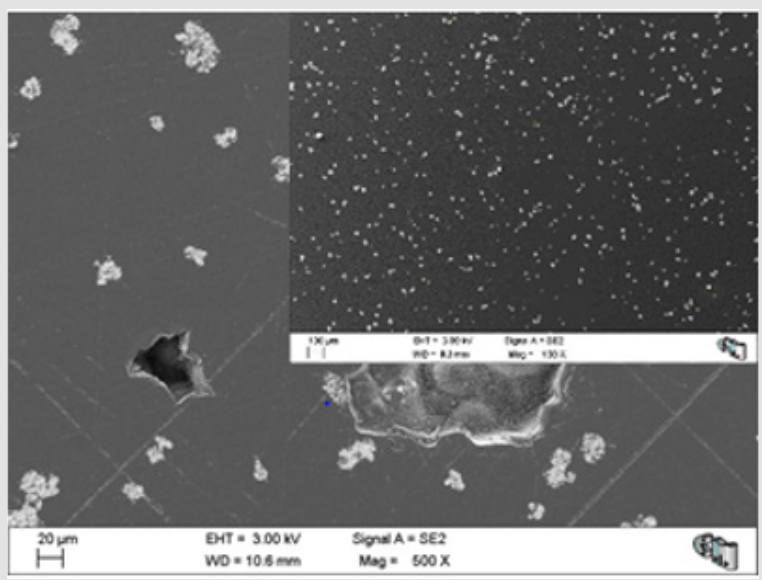

Figure 1: Microstructure of MAT 1.00. The pores (black/ grey holes) holes are several times larger than the radiopacifier particles (white dots).

Table 2: Mean value and mean quadratic error for temperature increment during curing, density, tensile strength, and fracture toughness as a function of wt. \% of HRGO platelets.

\begin{tabular}{|c|c|c|c|c|}
\hline Material & DT $\left({ }^{\circ} \mathbf{C}\right)$ & $\begin{array}{c}\rho \\
\left(\mathrm{g} / \mathbf{c m}^{3}\right)\end{array}$ & $\begin{array}{c}\sigma \\
(\mathbf{M P a})\end{array}$ & KIC $\left(\mathbf{M P a} \cdot \mathbf{m}^{\mathbf{1} / \mathbf{2}}\right)$ \\
\hline MAT R & $11,8 \pm 0,3$ & $1,244 \pm 0,002$ & $38 \pm 2$ & $1,28 \pm 0,02$ \\
\hline MAT 0.01 & $11,1 \pm 0,3$ & - & - & - \\
\hline MAT 0.10 & $8,5 \pm 0,3$ & $1,240 \pm 0,002$ & $36 \pm 4$ & $1,20 \pm 0,05$ \\
\hline MAT 0.50 & - & $1,229 \pm 0,009$ & $29 \pm 5$ & $1,12 \pm 0,02$ \\
\hline MAT 1.00 & $6.6 \pm 0.3$ & $1.236 \pm 0.002$ & $29 \pm 3$ & $0.99 \pm 0.04$ \\
\hline
\end{tabular}

\section{Conclusion}

From the analysis of the results, it is concluded that graphene's addition substantially lowers the material's curing temperature, avoiding or reducing the potential tissue damage during surgery. The addition of small percentages of graphene (HRGO) reduces the material's final density and enhances its porosity. Consequently, the mechanical properties of the new materials can be reduced by $20 \%$. Nevertheless, this unwanted side effect is not of concern 
as the residual mechanical strength of HRGO materials remains sufficiently high to fulfil their structural role.

\section{Conflict of Interest}

The authors declare no conflict of interest.

\section{Acknowledgements}

This work has been supported by the Spanish Government (PID2019-106631GB-C44, MICINN/FEDER, UE) and Comunidad de Madrid Government (P2018/NMT-4511 NMAT2D-CM, P2018/NMT-4411 ADITIMAT-CM, FEDER-UE). J. Orellana thanks scholarship provided by UPM and Ministerio de Educación, Cultura y Deporte of Spain (FPU17/02035). Y.Y. Pastor thanks Prof. J. Marco (UCM) for his continuous encouragement.

\section{References}

1. Bandelette GC, Zoarski G, Manca A, Masala S, Eminefendic H, et al. (2008) Percutaneous vertebroplasty and bone cement leakage: clinical experience with a new high-viscosity bone cement and delivery system for vertebral augmentation in benign and malignant compression fractures. Cardiovascular and interventional radiology 31(5): 937-947.

2. Künh KD (2014) Impact of Temperature on Cell Death in a Cell-culture Model of Hepatocellular Carcinoma. Anticancer Research 32(3): 915921.

\section{ISSN: 2574-1241}

DOI: 10.26717/BJSTR.2021.35.005646

Jose Ygnacio Pastor. Biomed J Sci \& Tech Res

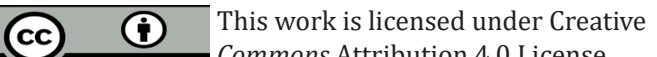

(cC) Commons Attribution 4.0 License

Submission Link: https://biomedres.us/submit-manuscript.php
3. Kuhn KD, Springer G (2013) PMMA Cements.

4. Vaishya R, Chauhan M, Vaish A (2013) Bone cement. Journal of clinical orthopedics and trauma 4(4): 157-163.

5. Frutos G, Pastor JY, Martínez N, Virto MR, Torrado S (2010) Influence of lactose addition to gentamicin-loaded acrylic bone cement on the kinetics of release of the antibiotic and the cement properties. Acta biomaterialia 6(3): 804-811.

6. Palacios T, Tarancón S, Abad C, Pastor JY (2021) Saliva Influence on the Mechanical Properties of Advanced CAD/CAM Composites for Indirect Dental Restorations. Polymers 13(5): 808.

7. Bandelette GC, Zoarski G, Manca A, Masala S, Eminefendic H, et al. (2008) Percutaneous vertebroplasty and bone cement leakage: clinical experience with a new high-viscosity bone cement and delivery system for vertebral augmentation in benign and malignant compression fractures. Cardiovascular and interventional radiology 31(5): 937-947.

8. Kuhn KD, Springer G (2013) PMMA Cements.

9. Vaishya R, Chauhan M, Vaish A (2013) Bone cement. Journal of clinical orthopedics and trauma 4(4): 157-163.

10. Frutos G, Pastor JY, Martínez N, Virto MR, Torrado S (2010) Influence of lactose addition to gentamicin-loaded acrylic bone cement on the kinetics of release of the antibiotic and the cement properties. Acta biomaterialia 6(3): 804-811. 